\title{
Matematização da Natureza: do SÉculo XVI ho XVIII
}

\author{
[MATHEMATiZATION OF NATURE: FROM THE 16TH tO THE 18H CENTURY]
}

\author{
Camila Maria Sitko * \\ Universidade Federal do Paraná, Brasil \\ Universidade Federal do Sul e Sudeste do Pará, Brasil \\ Instituto de Estudos Superiores de Fafe (CIDI-IESF), Portugal
}

\begin{abstract}
Resumo: Este trabalho tece uma linha temporal das mudanças sofridas com relação à forma de se ver a ciência e a matemática ao longo dos séculos XVI e XVIII. São abordadas as transições entre a ciência aristotélica e a ciência moderna. No intervalo em questão, houver diferentes tradições de pensamento, a inclusão dos números no pensamento científico, a tradição experimental baconiana, as crenças naturalistas, a chamada revolução científica e a universalização das leis mecânicas, a matematização da natureza e a unificação do que chamamos de física matemática. A partir desse apanhado histórico e filosófico, pode-se perceber que a ciência e a matemática sofreram mutações substanciais ao longo de suas construções históricas, a fim de tornar a natureza matematizada.
\end{abstract}

PalaVras-ChaVe: Matematização da natureza; Galileu Galilei; Revolução científica
ABSTRACT: This work weaves a timeline of the changes suffered in relation to the way of viewing science and mathematics throughout the 16th and 18th centuries. Transitions between Aristotelian science and modern science are addressed. In the interval in question, there were different traditions of thought, the inclusion of numbers in scientific thought, the Baconian experimental tradition, naturalistic beliefs, the so-called scientific revolution and the universalization of mechanical laws, the mathematization of nature and the unification of what we call mathematical physics. From this historical and philosophical overview, it can be seen that science and mathematics have undergone substantial mutations throughout their historical constructions, in order to make nature mathematized.

KEYWORDS: Mathematization of nature; Galileo Galilei; Scientific Revolution

\section{INTRODUÇão: A CIÊNCIA ANTIGA}

Antigamente, a ciência (era resumida à astronomia, estática e óptica) era praticada em conjunto com a matemática e a harmonia. A ciência do século $\mathrm{V}$ a.C. era concebida como o estudo das quantidades físicas reais, e era especialmente espacial (KUHN, 1989). A astronomia e a harmonia eram matemáticas, pois lidavam com posições e proposições. A estática e a óptica também tinham uma estrutura dedutiva e lógica. É devido a isso que homens como Arquimedes, Euclides e Ptolomeu contribuíram não só em uma área específica, pois elas estavam todas relacionadas. Essas áreas eram conhecidas como as ciências físicas clássicas (KUHN, 1989). Além destas,

* Doutora em Ensino de Ciências. Técnica de laboratório de Física da Universidade Federal do Paraná. Professora no Programa de Pós-Graduação em Educação em Ciências e Matemática da Universidade Federal do Sul e Sudeste do Pará. Investigadora do Centro de Investigação, Desenvolvimento e Inovação do Instituto de Estudos Superiores de Fafe (CIDI-IESF)-PT. E-mail: camilasitko@yahoo.com.br 
posteriormente, Koyré denomina outro grupo (experimental) como ciências baconianas. Em sua obra, Koyré divide a história do pensamento científico em etapas que podem ser definidas como: a física aristotétlica, a física do ímpeto, e a física moderna.

Embora as ciências clássicas, definidas dessa maneira por Kuhn (ou a aristotélica de Koyré) fossem empíricas, exigiam poucas observações e experimentação refinadas. Assim, observações empíricas cotidianas muitas vezes resolviam o problema. Não havia uma tradição experimental muito definida para essas áreas, com exceção de ramos em que havia um cunho social envolvido, como a medicina e a astronomia.

A física aristotélica era não matemática. Era uma teoria a partir do que se via, ou seja, do senso comum, que estabelecia uma sistematização, embora não matemática. Nessa física, ocorre a distinção entre movimentos "naturais" e "violentos", os quais estão em um cosmo, no qual todas as coisas tem um lugar definido: os movimentos violentos são aqueles que vão contra seu local natural. Tais movimentos são encarados como desordens cósmicas, e ocorrem de maneira transitória. Por exemplo, uma pedra lançada para o alto logo tende a cair, pois o chão é o seu local natural.

Além disso, no sistema aristotélico, há uma incompatibilidade entre a física do mundo real, concreto, e a geometria das abstrações (KOYRÉ, 1986). Seria um erro tentar aplicar a matemática à natureza: não existem nela círculos, triângulos, retângulos. Os gregos mediram os céus, mas isso porque era relacionado à astronomia, onde havia um mundo perfeito, e não o terrestre, dos objetos reais.

Prosseguindo na linha temporal, é possível notar desde o século IX a eficiência técnica na prática científica do Islão, se comparada à da Antiguidade. No século XIII, houve no Ocidente Latino o desenvolvimento matemático para tratar desses campos conceituais, numa tradição filosófico-teológica (KUHN, 1989)., que passou a ser objeto de pesquisa central durante o Renascimento europeu. A partir do século XVI, o problema do movimento passou a ser associado à matemática em vez da filosofia de mudança. Dessa forma, mesmo durante o Renascimento, e também depois desse período, as ciências clássicas continuaram a constituir um conjunto entrelaçado (KUHN, 1989). Aqui compreende-se que esta transição, comentada por Kuhn até o século XVI, é a mesma física do ímpeto de Koyré.

A física do ímpeto também era baseada em experiências cotidianas, mas completamente diferente da aristotélica, pois não mais explicava os movimentos por processos de atualização, mas sim com relação a uma causa determinada, algo que ultrapassava a resistência ao movimento, que era o ímpeto. $\mathrm{O}$ ímpeto era entendido como uma qualidade, o que tornava um pouco confusa a definição de sua natureza.

Em meio a essas descrições da natureza, surge Galileu, que se opõe ao ímpeto, mostrando que o mesmo era incompatível com o princípio de inércia, e com outros métodos matemáticos; aqui já se pode perceber a introdução do número como quantitativo na descrição os processos naturais. Esse processo levaria à matematização da ciência, e assim, aos poucos a ideia de ímpeto foi sendo esquecida, e em seu lugar, Galileu introduziu o movimento. A partir dessas mudanças, pode-se perceber que Galileu foi importante figura na transição para o período de ciência moderna. Mas além de Galileu, muitos outros, bem como muitas outras transições, foram fundamentais para que a matematização da natureza ocorresse.

Assim, neste texto, serão discutidas as mudanças com relação à concepção de ciência dos séculos XVI e XVIII, bem como são abordadas as transições ocorridas da ciência aristotélica para a ciência moderna, que incluíram diferentes correntes de pensamento, bem como a inclusão dos números no pensamento científico, a tradição experimental baconiana, as crenças naturalistas, a chamada revolução científica e a universalização das leis mecânicas, a matematização da natureza e a unificação do que chamamos de física matemática. O objetivo é tecer uma linha de raciocínio que mostra 
como a ciência e a matemática sofreram mutações ao longo do tempo, tornando a natureza matematizada, como hoje a compreendemos.

\section{Os SÉCULOS XV E XVI}

Koyré discute (1986) que durante a física medieval, havia a criação de artefatos e instrumentos, mas que estes não possuíam cientificidade. Nesse panorama, Bacon acreditava que a ciência seria um resumo do que foi constatado na prática. Por outro lado, Descartes já acreditava que haveria uma ligação entre a prática e a ciência. Para ele, o mesmo esforço realizado para montar e desmontar um equipamento, seria utilizado para montar e desmontar uma equação. É esse pensamento cartesiano que leva Koyré a concluir que no século XVII ocorre uma conversão da episteme na techné.

Durante os séculos XV e XVI, o que se pode observar é um "maquinário aproximado", no sentido de que não há precisão, padronização, nem matematizações que ofereçam modelos para isso. A tecnologia não pedia cálculos de precisão, pois a sociedade e o mundo eram "aproximados". Koyré traz o exemplo da química, a qual hoje realiza experimentos precisos, mas com o uso dos mesmos equipamentos da alquimia: isso mostra que não é o instrumento, mas sim a ideia de como utilizá-lo que faz a diferença, ou seja, o que falta é a cientificidade. Não é a utilização do objeto que lhe determina a natureza: é a estrutura (1986, p. 83).

Koyré (1986) cita como exemplo de revolução, a partir da técnica (com cientificidade), a luneta dos Lippertshey e Janssen, que era utilizada para um fim, mas que com Galileu, desvendou os céus. Na medida em que a vida na cidade se sobressaía à rural, a necessidade de medidas exatas do tempo foi se tornando maior. Além disso, para pesquisas científicas (nessa ciência moderna), a precisão também se tornava imprescindível. Devido a fatores como estes, ocorreu a introdução da precisão no mundo, através do cronômetro, pensado e elaborado por Galileu e Huygens.

\section{A reconstruÇão da CiênCIA}

A cada dia, novos fenômenos, materiais e descobertas eram trazidos à tona; limites de observação eram ultrapassados com o telescópio e o microscópio, e cada vez mais detalhes eram conhecidos, na medida em que ocorriam melhorias nos equipamentos. Práticas intelectuais exploraram a história natural e humana e trouxeram conhecimentos que ninguém havia imaginado (SHAPIN, 1996). Nisso, muitas entidades e explicações colocaram a doutrina ortodoxa numa situação desconfortável. A certeza já não pairava mais, pois a cada dia uma parte do desconhecido era descoberta.

Algo importante a mencionar é que essas ciências clássicas foram radicalmente reconstruídas (KUHN, 1989) entre os séculos XVI e XVII. A matemática saiu da geométrica para a álgebra e o cálculo; a Terra deixou de ser o centro do Universo e passou seu posto ao Sol; o estudo do movimento obteve leis novas; a óptica obteve novas teorias; entre outras reconstruções. Essas transformações conceituais estão diretamente relacionadas às mudanças de pensamento ocidental (KUHN, 1989).

Muitos pensadores afirmam que a ideia de utilizar informações adquiridas pelos sentidos para basear a ciência era algo novo no século XVII (KUHN, 1989). Do século XIII ao XVII, foram estabelecidas regras para se chegar a resultados conclusivos a partir da experimentação e observação.

Esse novo movimento experimental, muitas vezes chamado de baconiano (KUHN, 1989), não era uma expansão do anterior, mas sim era uma forma diferente de 
ciência empírica. É importante ressaltar que um método não substituiu o outro, mas por muito tempo, coexistiram.

Assim, no início do século XVII, o sentimento geral era de otimismo pela descoberta de um novo mundo. Podemos perceber isso pela obra The great instauration, de Francis Bacon (1620), onde ele representa a esperança de um corpo maior de conhecimento e a ampliação do mundo natural, rompendo assim com os esquemas filosóficos existentes (SHAPIN, 1996).

Os cientistas modernos preferiram um sistema de mundo que parecia uma máquina, tanto é que passaram a tratá-la como filosofia mecânica. Utilizar explicações mecânicas para a natureza era algo totalmente diferente do que era feito até então (SHAPIN, 1996). Entretanto, essa ideia não era tão diferente da adotada na física aristotélica. A natureza tem um plano e um modo de agir. O humano modifica ou imita essa tecnologia, assim como um tecelão imita o trabalho de uma aranha, por exemplo (SHAPIN, 1996).

Entretanto, anteriormente, os artifícios da natureza seriam superiores aos do homem, e não podiam ser comparados. Agora, com Bacon, não havia mais problemas em comparar o que era artificial e o que era natural; muito pelo contrário, havia grande otimismo com relação ao potencial do que o humano poderia fazer. No século XVII, muitos filósofos, entre eles Gassendi, Boyle e Descartes, apoiaram essa ideia.

O relógio pode ser um bom exemplo de maquinaria que fez o caminho inverso e mostrou ao mundo natural um padrão, que antes era contado pelos movimentos celestes, mas que agora era produzido pelo homem e tinha cada vez mais precisão. A mudança do feudalismo para o capitalismo e a vinda para o centro urbano fizeram com que cada vez mais essa contagem do tempo fosse importante para as pessoas. Assim, a maquinaria do relógio era comparada à do mundo natural. É uma metáfora para se compreender a natureza (SHAPIN, 1996).

Outro exemplo é que no século XVII, alguns cientistas defendiam a existência do vácuo e outros não, sendo divididos então entre os da filosofia mecânica e a aristotélica. Com o experimento da bomba de sucção, Torricelli trabalhou com esse conceito e também com o do peso do ar, o que também ia totalmente contra a ideia aristotélica, de que nem o ar nem a água em seus estados naturais teriam peso (SHAPIN, 1996). A partir dessa experiência e aquela com mercúrio, Torricelli comprovou a existência do vácuo e apresentou um equipamento que media o peso do ar, o barômetro, confirmando a visão mecânica da natureza (SHAPIN, 1996).

\section{NATURAlismo E A ENTRAda PARA O MECANiCISMO}

No Renascimento, era comum que se acreditasse em forças ocultas da natureza, como por exemplo, que os corpos se atraiam à distância devido a mecanismos ocultos. Os cientistas respeitavam e acreditavam em certas influências, como a dos corpos celestes, apesar de serem céticos com algumas questões específicas da astrologia.

As ciências clássicas sofreram mudanças que incluíram inicialmente esse misticismo, que foi rejeitado próximo da metade do século, e substituído pela filosofia corpuscular. As forças de Newton de atração e repulsão não eram bem aceitas nesse modelo, o universo já não tinha direções preferenciais (KUHN, 1989), movimentos naturais só ocorriam em linhas retas, e perturbações só ocorriam por colisões intercorpusculares.

As ciências baconianas também foram afetadas por esses movimentos, mas de maneira diferente: foram marcadas pelo retrato da figura do mago, querendo controlar a natureza, através de engenharias, que acabou transformando-se na ciência experimental. 
A experiência do século XVIII precisava de orientações a partir de conceitos que estavam relacionados ao oculto, como o flogisto. Mas o corpuscularismo separou as ciências experimentais da magia e "forneceu uma fundamentação lógica para a experimentação" (1986, p. 89).

Apesar da filosofia mecânica se mostrar oposta à filosofia aristotélica, o "naturalismo renascentista" (SHAPIN, 1996, p. 43) mostrou um modelo do que era ser oposto. Muitos que eram atraídos pelo mecanicismo ficaram perturbados pelas consequências do naturalismo nas práticas sociais e culturais no século XVII e XVIII (SHAPIN, 1996). Foi um pouco devido a esses processos de oposição que a concepção mecânica de natureza emergiu. Alguns filósofos, como é o caso de Mersenne, temeram esse reavivamento de vidas impregnadas na matéria, que levariam a heresias 1x. Assim, para Mersenne, era necessária uma metafísica apropriada para explicar a filosofia mecânica do mundo natural, utilizando uma matéria inanimada. Para várias versões de mecanicismo era importante que a matéria fosse vista como inanimada, e assim, Mersenne teve um papel importante nesse desenvolvimento. Essa visão foi principalmente desenvolvida por Descartes, Hobbes e Boyle. Entretanto, havia leigos que faziam oposição a esta, assim como havia várias versões de filosofia mecânica.

A base do pensamento mecanicista era a de que todos os efeitos genuínos na natureza tem uma explicação com base em causas ordinárias, compreensíveis e mecânicas (SHAPIN, 1996). Havia algumas crenças, como simpatias, por exemplo, que pairavam na sociedade da época. Boyle desconfiava de que as curas, por exemplo, eram realizadas por forças totalmente ocultas, e assim, tentava explicá-las da maneira mecânica, e se ainda assim houvesse algo inexplicado, deveria ser direcionado a Deus, e não a forças misteriosas (SHAPIN, 1996).

Os filósofos do século XVII passaram a utilizar apenas a explicação mecânica para a natureza. Era nova a ideia de que os princípios de matéria e movimento seriam recursos de definição para a filosofia natural. Se houvessem propostas de filosofia natural que tivessem como base algo além de movimento e matéria, havia o risco de não serem consideradas filosóficas. Apesar disso, as especificidades de uma explicação mecânica e outra mudavam de um filósofo para outro.

Como no caso do uso e melhoramento do microscópio, uma infinidade de elementos foi descoberta, como superfícies que aparentemente eram lisas, e no instrumento apareceram rugosas; a composição do sangue por glóbulos, etc (SHAPIN, 1996). Hooke mostrou que com o microscópio, que revela as particularidades da matéria, as qualidades "ocultas" deveriam ser ignoradas (SHAPIN, 1996).

O corpuscularismo cada vez mais se tornou uma forte maneira filosófica de pensar a respeito da matéria, justamente devido ao que o microscópio podia revelar. De fato, os resultados eram compatíveis com a teoria corpuscular. $O$ mecanismo corpuscular, dessa forma, abrangia uma grande gama de explicações gerais e específicas (SHAPIN, 1996). Os filósofos corpusculares e mecânicos queriam explicar as propriedades dos corpos, e nesse sentido, a explicação mecânica era a única inteligível.

As qualidades seriam separadas entre primárias e secundárias. As primárias seriam aquelas que realmente pertencem ao objeto, como tamanho e movimento (SHAPIN, 1996). As qualidades secundárias seriam derivadas das primárias, como doçura, a cor, se é quente ou frio, etc. As qualidades primárias produziriam esses efeitos subjetivos em nós (SHAPIN, 1996). Essas ideias de qualidades secundárias nada mais seriam do que o efeito que os movimentos e os objetos causariam em nós.

Há então uma diferença entre o senso comum e o domínio da filosofia, assim como no sistema de Copérnico. Nesse sentido, a experiência sensória não seria confiável a fornecer ao sujeito a ideia de como o mundo realmente seria. Assim, os 
filósofos mecânicos se colocavam contra a experiência e o senso comum e também contra a doutrina aristotélica das "qualidades reais" (SHAPIN, 1996).

Uma estátua de mármore, por exemplo, você pode construir qualquer coisa com esse material. A forma será o objeto. Mas não para os aristotélicos, para eles, as formas eram as entidades reais, como Alexandre ou algum deus. Para eles, haveria uma correspondência entre como o mundo era e como nós o experienciamos (SHAPIN, 1996).

Assim, os filósofos mecânicos iam contra a ideia de formas substanciais e afirmavam que suas explicações eram as únicas inteligíveis, e isso os beneficiou. Essas explicações tem um caráter estrutural, ou seja, a explicação sobre uma entidade tem a ver com sua constituição e comportamento. Com essas explicações, os filósofos agora não queriam explicar apenas alguns fenômenos, mas todos.

\section{MÉtodo BaConiano}

Na experimentação antiga, muitos experimentos eram "de pensamento" (KUHN, 1989 , p. 75), e os que eram realizados, ou era para confirmar uma conclusão já préestabelecida, ou para fornecer respostas concretas a questões propostas pelas teorias existentes. A nova tradição experimental lidava com situações reais, e inclusive desprezava as experiências mentais (KUHN, 1989). Por exemplo, antes de Tycho Brahe, os astrônomos não faziam experimentações sistemáticas do céu, apenas registravam eventos.

A diferença no método baconiano é que neste os cientistas não buscam comprovar teorias e o que já é conhecido, mas buscavam ver como a natureza se comporta em situações ainda não observadas (KUHN, 1989).

Em geral, o método de experimentos já era pré-determinado, pois nessa época havia a vertente dos filósofos atomistas e a dos corpusculares, e assim, estes buscavam experimentos que fossem condizentes com sua metafísica.

Nessa nova tradição experimental baconiana, a natureza era colocada em situações que jamais poderiam ser alcançadas sem a interferência do homem. A criação de novos instrumentos experimentais também é uma novidade dessa tradição; até 1590, havia somente aparelhos para observação astronômica. Assim, "em menos de um século, a ciência física tornou-se instrumental” (KUHN, 1989, p. 78).

Entretanto, as contribuições do baconianismo para o desenvolvimento da ciência foram muito pequenas, pois a maior parte dos experimentos tinham origem nos medievais, ou mesmo eram confirmação de resultados já previstos anteriormente. Assim, a transformação das ciências clássicas durante a Revolução Científica está mais relacionada a uma nova forma de olhar para os fenômenos já conhecidos do que a novas descobertas experimentais (KUHN, 1989). Ainda assim, o baconianismo deu origem a novos campos científicos, como o magnetismo e a eletricidade, pois além de relações que deveriam ser encontradas, esses campos precisavam do desenvolvimento de novos instrumentos e técnicas.

No século XVIII, entretanto, a experimentação se tornou mais sistemática (KUHN, 1989). As teorias que sustentavam esses experimentos ainda eram qualitativas, entretanto, podiam ser confrontadas com experimentos individuais e mostravam uma precisão não encontrada na ciência baconiana. E na medida em que os aperfeiçoamentos davam margem para mais confrontos, mais a ciência baconiana se tornava como a da Antiguidade.

As ciências clássicas e as baconianas permaneceram separadas por muito tempo; as

primeiras eram consideradas matemáticas e as segundas como filosofias 
experimentais (KUHN, 1989). Bacon desconfiava da matemática, que processos tão complexos e abstratos não poderiam ser úteis para a compreensão da natureza.

Ao final do século XVII, muitos novos instrumentos adentraram nesses campos de estudo, assim como novos critérios de avaliar dados. Os efeitos percebidos foram mais no sentido de "refinamento gradual do que uma mudança substancial na natureza das ciências clássicas" (KUHN, 1989, p. 83). Embora nesse processo a lacuna entre as ciências baconianas e as clássicas tivesse diminuído, não havia desaparecido. No século XVIII, aqueles que praticavam as ciências matemáticas realizavam poucas experiências e poucas contribuições no sentido de desenvolver novos campos experimentais (KUHN, 1989).

Apesar de Galileu, no século XVII, ter desenvolvido equipamentos e falar muito da ciência experimental, sua atitude era em defesa das ciências clássicas, quando afirma que não há a necessidade de realizar os experimentos que idealiza (KUHN, 1989). Já em outras situações, quando um equipamento limitava o que ele pretendia fazer, desenvolvia outros a fim de chegar à conclusão necessária.

Já Newton, no século XVIII, participou de ambas as tradições. Os Principia são uma obra da vertente da ciência clássica, mas seus estudos em óptica mostram uma ciência baconiana, justapondo resultados de experimentos a teorias, elaborando novas. Newton fez o uso do experimento baconiano com um uso não baconiano, que mostra a imersão deste nas duas tradições (KUHN, 1989). Newton foi praticamente o único que permeou as duas vertentes.

Durante os séculos XVII e XVIII o número de cientistas que contribuíram para as ciências clássicas aumentou, e estes eram profissionais. Já as ciências baconianas eram praticadas por amadores, farmacêuticos, etc. Embora alguns desses tivessem posições nas academias científicas, eram posições de segunda classe, até o fim do século XIX.

Uma das principais diferenças entre as ciências clássicas e as baconianas, como podemos ver no contraste entre Leonardo Da Vinci, Newton e Descartes, e Bacon, Boyle e Hooke, é o utilitarismo; os primeiros não se preocupavam se seus instrumentos funcionaram e para que, diferentemente do segundo grupo (KUHN, 1989). Retornando ao século XVII, as ciências baconianas estavam em processo de formação ainda, e as ciências clássicas passaram por grandes mudanças; é o período que conhecemos por Revolução Científica (KUHN, 1989).

\section{REVOLUÇ̃̃o CIENTÍFICA}

Há uma controvérsia entre os historiadores e filósofos da ciência com relação ao uso do termo revolução científica para descrever mudanças científicas. Ainda que adotemos o uso do termo revolução sem questioná-lo, outra controvérsia aparece, que é com relação a quando esta teria ocorrido. Alguns acreditam que foi com Newton, outros defendem que foi com Galileu, e outros ainda acreditam que tenha sido com Descartes, dentre outras hipóteses (COHEN, 1980).

Independentemente de se pensar quem foi o precursor da revolução, o fato é que a nova ciência e a filosofia que emergiram durante o século XVII podem ser distinguidas daquelas de períodos anteriores, tanto por fatores externos como internos (COHEN, 1980).

Alguns dos fatores externos que diferenciam esse período é que agora existia uma comunidade científica, com organizações e recursos financeiros estatais, utilizando os mesmos métodos e dedicados à busca por conhecimento, a partir da experimentação. A forma encontrada pelos cientistas de alcançar esses objetivos foi com $o$ 
estabelecimento de revistas e sociedades científicas (COHEN, 1980). Quanto aos fatores internos, a revolução pode ser percebida através dos métodos e resultados.

A ciência antes era tradicionalmente prática e servia à religião. A nova ciência tinha o objetivo de melhorar a vida cotidiana. Outra característica importante da revolução era a atenção dada ao método. Vários cientistas, como Descartes, Bacon, Huygens, Newton, preocuparam-se em estabelecer um método de se fazer ciência de forma direta e infalível (COHEN, 1980). Era um método experimental e não meramente observacional, que poderia levar a princípios matemáticos. A partir do método, qualquer um que tivesse o equipamento e as instruções deveria ser capaz de reproduzi-lo. Essas pesquisas e experimentos reprodutíveis levaram a uma maior compreensão dos fenômenos.

A partir disso, os cientistas passaram a reproduzir experimentos de outros para seus próprios fins, e os experimentos que não eram reprodutíveis não eram ciência, pois esta deveria ser reprodutível e sujeita a leis universais. Além disso, nessa nova ciência, as leis que não se aplicavam ao mundo real não tinham real importância. O que se nota nessa transição é que o homem já não buscava mais contemplar a natureza apenas, mas dominá-la (KOYRÉ, 1986), e que Galileu esteve a frente disso: sua revolução e de Descartes revolucionaram a técnica da ciência artesã.

As ciências clássicas foram praticamente as únicas que se transformaram, uma vez que as demais sequer existiam nessa época, ou existiam sem um corpo de técnicas estabelecido para serem reconstruídas (KUHN, 1989). A introdução de novos artifícios intelectuais é um exemplo das mudanças ocorridas. Tentativas de encontrar regularidade na natureza foram estabelecidas, assim como as formas matemáticas foram colocadas como as causas formais do fenômeno, e cada vez mais os cientistas modernos davam valor a essa ferramenta (a matemática) como ontologia (KUHN, 1989).

Todavia, não foi somente a mudança intelectual que fomentou a Revolução Científica, muitos outros fatores complexos estavam envolvidos. Por exemplo, agora com novos modos de vida renascentistas, os artífices e técnicos adquiriram riquezas e foram a outro patamar; a invenção da imprensa permitiu que os materiais dos antigos estivessem disponíveis a todos, e não mais somente no ambiente clerical. A partir disso, esses homens agora tinham patrocínio para suas pesquisas, eram empregados e ao mesmo tempo chamarizes de seus governos; nesse grupo estavam Leonardo, Galileu, e Stevin (KUHN, 1989).

Contudo, apesar de terem um pé no método baconiano, as fontes utilizadas por esses membros eram do grupo clássico. Seja como artistas ou como engenheiros, eles exploraram as obras de matemática, estática, óptica, o que foi um fator relevante para a reconstrução das ciências baconianas. As preocupações da engenharia ajudaram a separar os problemas de movimentos locais do problema filosófico mais geral a respeito da mudança (KUHN, 1989). As preocupações dos artistas-engenheiros renascentistas não estavam em incluir aspectos que não fossem mecânicos ou matemáticos, como as técnicas de tecelagem, fabricação de vidros, etc.; mas as novas ciências experimentais tiveram seu surgimento justamente nessas técnicas (KUHN, 1989).

\section{CARACTERÍSTICAS DA NOVA CIÊNCIA}

A nova ciência tinha como importantes características a observação e a experimentação, como bem pode ser observado no episódio da luneta de Galileu e a observação do céu, a qual provocou uma verdadeira revolução nas concepções da época (KOYRÉ, 1986).

Tal experimentação possuía critérios bem definidos de realização, que 
consistiam (e consistem até hoje) em uma interrogação sistemática da natureza, através do uso de uma linguagem objetiva, que seria a matemática. A linguagem utilizada por Galileu era a geométrica. Nessa etapa, pode-se perceber claramente a mudança das concepções de mundo e de como se fazer ciência sofridas: a natureza agora era matematizada, e as leis que a regiam eram universais, pois já não havia mais a distinção entre mundo sub e supralunar.

No século XVII, não somente nas áreas exatas, mas também nas biológicas, o uso de números foi introduzido. Na Biologia, Harvey, por exemplo, analisou o fluxo de sangue no corpo, numerando a quantidade de pulsos que o coração faz em cerca de uma hora.

As relações numéricas eram proeminentes nessa época porque as leis da ciência ainda não eram descritas por meio de equações. Juntamente aos números, a matemática do século XVII era acompanhada de geometria. As obras de Galileu e o movimento acelerado, ou Newton e as leis do movimento, nada disso era descrito em proporções algébricas, mas em formato geométrico, ou também como Newton o fez, por séries infinitas.

Além da busca por números especiais, os cientistas do século XVII também buscavam relações exatas entre números obtidos a partir da experimentação. Por exemplo, tanto Galileu quanto Kepler eram convencidos de que as velocidades com que os planetas giravam em torno do Sol faziam parte de uma relação específica proposta por Deus, durante a criação. Kepler então estudou o problema e chegou à relação que hoje conhecemos como Terceira Lei de Kepler. Essa é a diferença entre o século XVII e os anteriores: o uso de relações numéricas, mas agora com relação à experimentação e à observação; as relações são baseadas na natureza.

Conforme salienta Cohen, hoje sabemos que Galileu fazia os experimentos não só para relacionar suas descobertas com a natureza, mas seus experimentos eram "parte do processo de descoberta em si" (COHEN, 1980).

É possível observar certa hierarquia de leis matemáticas na ciência do século XVII. São leis deduzidas a partir de definições e suposições que levam a resultados experimentais passíveis de testes (COHEN, 1980). Era comum que as causas dos movimentos não fossem explicadas: o que importava é que as leis matemáticas fossem condizentes com a experimentação.

Criar uma ciência física baseada na matemática era algo novo para o século XVII (COHEN, 1980). Outro fator que diferenciava a nova ciência da antiga é que os modelos antigos eram fictícios, e agora, os cientistas explicavam a realidade. A matemática serviu não só para medir posições a ângulos, mas para quantificar qualidades como a temperatura e velocidade. O objetivo era expressar leis gerais da natureza como relações matemáticas, conhecimento que viria da experimentação e observação da realidade.

Entretanto, houve certo avanço, outro tipo de hierarquia, que tentava explicar as causas dos fenômenos, como é o caso de Boyle, que utilizou modelos físicos para explicar sua lei que relacionava volume e pressão de um gás confinado. Esse tipo de explicação mostra uma diferença entre as afirmações matemáticas, ou seja, a descrição matemática de um fenômeno, e um mecanismo que explica o fenômeno, ou seja, uma exploração física e matemática de suas causas (COHEN, 1980).

No caso da gravitação de Newton, este mostrou que a descrição matemática da lei era a condição causal do movimento. Newton trabalhava as consequências matemáticas das suas equações relacionadas a condições físicas, sem discutir a realidade física destas.

Os testes eram verificações das predições ou não predições de certas ocorrências, como eclipses e configurações planetárias, e estes só podiam ser precisos 
ao se fazer uso de uma base de dados numérica. Mas para isso, era necessário que não houvesse preocupação com as causas físicas.

\section{Descartes a Galileu}

Galileu e Descartes foram alguns dos responsáveis pela implementação do número como um elemento do saber exato, conforme discorre Koyré (1986). Entretanto, essa tarefa não foi trivial. Seus conceitos de espaço e movimento eram muito diferentes daqueles da física aristotélica, e, dessa forma, eram agora objetos matemáticos, e não mais objetos onde se aplicava a matemática.

Para os aristotélicos, a natureza tinha um caráter qualitativo que não poderia ser expresso em números; e realmente, o que foi necessário na ciência de Descartes e Galileu foi justamente o afastamento da qualidade do domínio da natureza (KOYRÉ, 1986). O ponto chave da ciência galileana é que ela juntou os movimentos e os números, encontrando uma ciência do mundo concreto, mas que é feita pela dedução e pelo raciocínio.

Quando Galileu apontou seu telescópio para o Sol, observou nele certas manchas, que ora estavam em um local e ora em outro. Ele não tinha certeza do que elas eram, mas sabia que estavam no Sol, ou muito próximas dele. Isso era uma atitude desafiadora com relação à ortodoxia da época, que acreditava que tudo entre a Terra e a Lua era imperfeito e mutável, mas que a partir da Lua, os movimentos eram apenas circulares e não havia imperfeição (SHAPIN, 1996).

Galileu argumentou contra esse sistema aristotélico de perfeição supralunar, mostrando que o Sol possuía manchas e que haveria imperfeição tanto nos céus quanto na Terra. Assim, estabeleceu uma nova maneira de pensar a respeito da natureza. Para ele, o conhecimento sobre o mundo deveria ser advindo de descobertas, observações e raciocínios matemáticos. A defesa de Galileu era a de que não existe um sistema de tratamento para os fenômenos dos céus e outro sistema para os fenômenos da Terra, mas um único sistema universal (SHAPIN, 1996). Outros cientistas dessa mesma posição também afirmavam que para se estudar movimentos era possível fazê-los artificialmente, ou seja, o que hoje chamamos de modelagem.

A pesquisa de Galileu serviu para dar crédito ao modelo heliocêntrico proposto por Copérnico, no século XVI. Antes de Copérnico, ninguém havia questionado o modelo geocêntrico e antropocêntrico de Ptolomeu (SHAPIN, 1996). Nesse modelo, a vida terrena era considerada vil e limitada, enquanto o resto do universo era perfeito e incorruptível. Essas ideias estão diretamente relacionadas à concepção da Igreja.

Nos séculos XVI e XVII, críticos do modelo geocêntrico colocaram a Terra e todos os outros planetas para orbitar o Sol, rejeitando o antropocentrismo. Até mesmo a ideia de outros mundos com outros tipos de humanos foi lançada. Com isso, os astrônomos modernos estenderam a escala do universo.

Quando Galileu viu as estrelas pelo telescópio, elas não mudaram o tamanho, o que levava a crer que estariam muito longe da Terra, estando de acordo com o modelo copernicano. Dessa forma, os astrônomos acreditavam que quanto melhor fosse o equipamento, cada vez encontrariam mais corpos celestes (SHAPIN, 1996). Apesar de Copérnico não ter anunciado um universo infinito, agora essa era a hipótese dos cientistas, no século XVII.

Por outro lado, enquanto os modernos astrônomos até comemoravam essa possibilidade de universo, os tradicionais tinham um grande desconforto em acreditar em um universo infinito que se movimenta, e que tem a Terra como apenas mais um corpo. 


\section{MATEMática Na NOVA CIÊNCIA}

Kepler não estava satisfeito com os modelos astronômicos de seus antecessores. Ele queria "salvar os fenômenos" (COHEN, 1980, p. 35), ou seja, derivar o movimento dos planetas a partir de suas forças, que seriam as causas desse movimento. Ele buscou então uma descrição dinâmica em vez da cinemática para sua astronomia. Outros, como Descartes, também buscavam essas explicações causais, mas em sua maioria, os cientistas se preocupavam mais com relação às predições dos fenômenos e da observação (COHEN, 1980).

Newton conseguiu estabelecer uma dinâmica matemática de acordo com as leis cinemáticas fenomenológicas (COHEN, 1980), mostrando as causas físicas uma na outra. Kepler começa das causas, enquanto Newton conclui nas causas. Ou seja, Newton saía dos efeitos para chegar às causas; dos particulares para os gerais, enquanto Kepler saía dos gerais para os particulares. Para Cohen (1980), foi essa capacidade de Newton que produziu um resultado impressionante nos Principia e inaugurou a época da chamada revolução na ciência, que já havia começado, mas imperfeitamente, com Galileu e Kepler.

Às vezes é dito que a mecanização do mundo implicava em uma concepção matemática da natureza. A visão mecânica certamente foi responsável pela matematização. Alguns dos filósofos insistiam no papel central da matemática (SHAPIN, 1996). Contudo, apesar de defenderem o uso da matemática, muitos deles não eram matematizados, e sua habilidade de expressar matematicamente as quantidades mecânicas era comprometida. Ou seja, apesar de saberem a importância disso, ainda assim as conexões entre as duas áreas ficavam comprometidas.

Nos séculos XVI e XVII havia uma divergência com relação a se a abordagem matemática era obrigatória, contraposta por filósofos que afirmavam que a matemática não era capaz de expressar as complexidades do mundo natural (SHAPIN, 1996).

Alguns eram críticos a respeito da idealização matemática, como Bacon e Boyle, que diziam que as explicações matemáticas funcionavam muito bem com situações abstratas, mas não tanto com situações concretas (SHAPIN, 1996). A lei de queda de corpos de Galileu, por exemplo, funciona num ambiente ideal, e na situação real é apenas aproximada. Dessa forma, então surge o questionamento de se a filosofia natural se concentra no domínio da matemática ideal ou do particular real (SHAPIN, 1996).

Ao propor um esquema de sistema solar com os cinco sólidos geométricos, Kepler acabou por dar confiança aos modelos de natureza que afirmavam que esta obedecia às leis matemáticas, criando uma concepção matemática da filosofia natural. Os cientistas queriam mostrar padrões formais do mundo natural, e a maior obra nesse sentido foram os Principia. A máquina do mundo obedecia a leis matemáticas, as quais eram descritas nessa obra. Assim, "matemática e mecanismo deveriam ser fundidos numa nova definição de filosofia natural apropriada" (SHAPIN, 1996, p. 61). Newton consolidou o impulso tomado por Galileu. Os Principia unificaram a matemática com os movimentos celestes e terrestres. A ideia levantada por Galileu ao mostrar as manchas solares foi consolidada com Newton, que muitos afirmam ter "destruído o cosmo" aristotélico (SHAPIN, 1996).

Nessa visão newtoniana, não havia mais a distinção aristotélica entre o que ocorria no céu e na Terra, e elas estavam unidas pela geometria. Agora, a natureza era descrita em termos do abstrato e absoluto, e não mais do local. A certeza nesse modelo era a física, observável, e a ferramenta para se alcançar os resultados era a matemática.

Uma interpretação da visão newtoniana é que as causas eram colocadas de lado, pois a matemática funcionava em explicar o que acontecia, sem a necessidade de uma explicação causal; entretanto, outra vertente afirma que ele expandiu o alcance da 
explicação mecânica causal (SHAPIN, 1996).

Contudo, em alguns assuntos que Newton não compreendia bem, como magnetismo e eletricidade, ele chamava a atenção para forças ocultas, entretanto, afirmando que não estava indo contra o modelo de mecanicismo. Isso foi muito criticado por Leibniz, que afirmava que Newton, utilizando seu prestígio político e religioso, estava trazendo à tona novamente algo oculto, já ignorado há muito tempo. Para cientistas como Leibniz, era imprescindível que se tivesse uma explicação causal, o que Newton não tinha a respeito da gravitação; isso na visão de Leibniz era uma explicação ininteligível e oculta. Mas a inteligibilidade e confiança nos preceitos de Newton é que a lei funcionava. Ela podia ser utilizada como explicatória mesmo que as causas da gravitação não fossem expostas (SHAPIN, 1996).

Assim, não se tem clara a noção se Newton reintroduziu as forças ocultas, ou se iniciou uma nova filosofia mecânica natural. No fim do século XVII, e no século XVIII, os cientistas passaram a debater justamente essas conquistas de Newton. Os filósofos mecânicos afirmavam que suas inovações eram mudanças radicais com relação ao conhecimento tradicional.

\section{MATEMATiZaÇÃo da NATUREZA E O SÉCULO XVIII}

$\mathrm{Na}$ época do Iluminismo, a Mecânica foi desenvolvida por geômetras e algebristas de maneira matemática, a partir de axiomas e deduções matemáticas. Neste sentido, a matematização é quando um objeto da ciência se torna matemático, ou seja, quando é necessário um modelo, um esquema que o descreva, e isso se torna o próprio objeto real. Panza defende (2002) que a aplicação da matemática na ciência do movimento tem sido feita desde Aristóteles, entretanto, a matematização não ocorreu antes de Newton. Galileu também não lidava com objetos matemáticos, mas aplicava a matemática a fenômenos naturais.

Para Panza (2002), a ideia de que a matemática ajuda a ciência a conseguir resultados é um pouco equivocada, ou também, conforme Pulte (2001), a matemática não representa os fenômenos físicos, não é um instrumento de explicação. $O$ movimento, por exemplo, era um conceito matemático, e não uma matemática aplicada ao fenômeno; era uma entidade matemática. Newton queria dizer isso, daí o nome princípios matemáticos da filosofia natural e o tratamento da mecânica como racional. É importante perceber que mesmo a Mecânica Analítica (de Euler, Lagrange, Bernoulli, d'Alembert) nunca foi matemática pura, mas tinha significado físico (PULTE, 2001).

A diferença para a nova física é que agora os cientistas não tentavam mais descobrir e explicar leis através de raciocínios, mas investigar a própria natureza, reproduzindo-a com experimentos.

Geralmente, a filosofia da ciência descreve a mecânica do século XVII e XVIII como uma tomada e consciência da importância da aplicação matemática a partir de um resultado experimental. Entretanto, Pulte salienta que não se pode esquecer da "natureza matemática da natureza" (PULTE, 2012, p. 184), pois foi justamente essa compreensão que mudou o direcionamento do século XVIII, levando a uma ciência matemática.

Alguns veem a matemática como uma ferramenta para predizer modelos e leis, que representam fenômenos físicos. É como se a matemática fosse um "co-produto" da ciência experimental, como se dependesse da experimentação e dados observacionais. Entretanto, a aplicação matemática é muito diferente da filosofia mecânica que se instaurava no século XVIII. Aplicação é algo que se refere a uma adaptação de entidades diferentes, e não é isso que significa a matematização da natureza, pois esta já 
é pensada desde o começo matematizada (PULTE, 2012).

No mecanicismo, o objetivo era determinar movimentos de partículas sob diferentes condições, e nesse sentido, o movimento era um ente matemático, e dessa forma, a ciência tinha que ser considerada não só experimental, mas também matemática (PULTE, 2012).

A mecânica racional, já mencionada por Newton, nunca foi considerada artificial, ou um exercício matemático formal sem significado (PULTE, 2012). Assim, os conceitos deduzidos eram esperados em situações empíricas. O mesmo é válido para a mecânica racional na forma analítica, que emergiu no século XVIII. Os símbolos, as fórmulas, as operações matemáticas, todos se referiam ao movimento e à matéria (PULTE, 2012).

É dito que a mecânica newtoniana teve sucesso devido ao seu êxito empírico. Entretanto, conforme Pulte destaca (2012), pode ser verdadeiro para a lei de gravitação, mas não para as fundações da mecânica, pois no século XVIII, muitos outros tiveram sucesso, mas não foi devido à experimentação, mas sim à racionalização e à matematização.

O século XVIII esteve inflado de princípios e leis. Estes eram trazidos por programas diferentes, confirmados por aplicação a diferentes problemas; não eram deduzidos de princípios "maiores" (2012, p. 190), nem deduzidos a partir de fenômenos. Em resumo, esses princípios não eram nem advindos da metafísica, nem do empirismo, mas deduzidos de uma física matemática. Assim, os esforços da época eram no sentido de estabelecer um único sistema de ordem (PULTE, 2012).

Euler foi um dos mais importantes matemáticos do século XVIII, pois desenvolveu novos conceitos e princípios da mecânica racional, colocou os conceitos newtonianos em uma matemática formal e ampliou seu campo de atuação. Euler utiliza um pouco de cada programa, na busca da organização de um sistema dedutivo (PULTE, 2012; SITKO, 2019), e chega ao cálculo das variações.

Nessa busca do século XVIII por um sistema dedutivo, não é mais suficiente ter axiomas certos e evidentes, mas é importante que o conhecimento mecânico se encaixe nesses axiomas (PULTE, 2012). O foco não é como chegar a esses axiomas, mas sim é na estrutura dedutiva do corpo de conhecimento.

Com a invenção do cálculo das variações, a união dos diferentes programas e a transformação das leis de Newton, Euler estabelece um sistema dedutivo como o almejado (SITKO, 2019). Com o estabelecimento desse novo programa, as fundações filosóficas passaram a ser ignoradas, uma vez que os axiomas formais são mais válidos que as leis da natureza, ou a verdade formal mais válida que a verdade material (PULTE, 2012). Nessa etapa, há um declínio do esforço em se buscar discussões metodológicas e metafísicas, e um aumento no esforço de buscar técnicas matemáticas e sistemas dedutivos apropriados.

Por exemplo, a natureza do espaço, tempo, força de gravitação, isso tudo era preocupação da primeira metade do século; na segunda metade, as preocupações eram técnicas, no sentido de cálculo de variações, equações diferenciais. Nessa fase, a mecânica racional foi transformada de uma filosofia matemática da natureza para uma “representação matemática autossuficiente do conhecimento mecânico" (PULTE, 2012, p. 193).

Nesse período de transição entre os séculos XVII e XVIII, discursos sobre os limites da ciência eram impossíveis e a matemática se tornou cada vez mais importante para a mudança de visão de ciência. A matemática tornou acessíveis os resultados de um programa de pesquisa a outro (PULTE, 2012). Também era a única capaz de integrar todos os princípios a partir dos quais as leis físicas poderiam ser derivadas, ou seja, a matemática integrava os diferentes programas. E assim, ao fim do século XVIII, 
tem-se apenas um sistema que representa todos os princípios de filosofia natural, que é a obra de Lagrange, Mécanique Analytique (PULTE, 2012).

A obra de Lagrange marca o final do desenvolvimento desses sistemas dedutivos. Seu método era totalmente demonstrativo, sem interpretações, intuições, figuras, nem reflexões filosóficas explícitas. Nessa época, o interesse não estava mais em fundações conceituais da mecânica, mas em lógicas coerentes, muito mais que verdades materiais (PULTE, 2012).

\section{CONSIDERAÇÕES FINAIS}

A ciência passou for grandes mudanças ao longo dos séculos XVI e XVIII, saindo de uma perspectiva artesã, de mundo aproximado, passando pelo naturalismo renascentista, o mundo experimenta baconiano, até uma perspectiva de natureza matematizada, precisa e abstrata, advinda de Descartes Galileu, Newton, Euler, etc. Tais mudanças ocorreram devido a uma série de fatores e de cientistas, como pôde ser observado neste trabalho.

Pode-se afirmar que a ciência mudou, mas ao mesmo tempo, que a natureza também assim o fez: a natureza tornou-se sistematizada, precisa e matematizada, advinda da observação e experimentação, no que passou a ser chamado de filosofia natural, a qual deu origem a leis gerais e sistematizações que descrevem os movimentos, e que são utilizadas até os dias de hoje.

\section{REFERÊNCIAS}

COHEN, I. Bernard. The newtonian revolution. With illustrations of the trasformation of scientific ideas Cambridge University Press, 1980.

KUHN, Thomas. A tensão essencial. Tradução Rui Pacheco. Lisboa: Edição 70, 1989.

KOYRÉ, Alexandre. Galileu e Platao e Do Mundo do "mais ou menos" ao Universo da Precisão. Tradução revista por José Trindade Santos. Gradiva, 1986.

PANZA, Marco. Mathematisation of the Science of Motion and the Birth of Analytical Mechanics: A Historiographical Note. In: CERRAI P., FREGUGLIA P., PELLEGRINI C. (eds) The Application of Mathematics to the Sciences of Nature. Springer, Boston, MA, 2002.

PULTE, Helmut. Order of Nature and Orders of Science. In: LEFÈVRE W. (eds). Between Leibniz, Newton, and Kant. Boston Studies in the Philosophy and History of Science, v. 220. Springer, Dordrecht, 2001.

PULTE, Helmut. Rational Mechanics in the Eighteenth Century. On Structural Developments of a Mathematical Science. Ber. Wissenschaftsgesch. 35, 183-199, 2012.

SHAPIN, Steven. The scientific revolution. Chicago: The university of Chicago Press, 1996.

SITKO, C. M. Why Newton's Second Law is not F = ma. Acta Scientiae, v. 21, n. 1, p. 83-94, 2019.

\section{Notas}

1 Para Aristóteles, os movimentos ocorriam até que os corpos ficassem em seus estados naturais. Os críticos do século XVII afirmavam que essa ideia é como se colocássemos atitudes humanas nos objetos, como se uma pedra soubesse onde era seu lugar correto e fosse até ele. Dessa forma, a partir dessa época, muitos passaram a ser sarcásticos com a física aristotélica (SHAPIN, 1996). 